\title{
Treatment of the Arthritic Valgus Ankle
}

\author{
Alexej Barg, $M D^{a, b, *}$, Geert I. Pagenstert, $\mathrm{MD}^{\mathrm{a}}$, \\ André G. Leumann, $\mathrm{MD}^{\mathrm{a}}$, Andreas M. Müller, $\mathrm{MD}^{\mathrm{a}}$, \\ Heath B. Henninger, $\mathrm{PhD}^{\mathrm{b}}$, Victor Valderrabano, $\mathrm{MD}^{\mathrm{Ah}} \mathrm{Ph}^{\mathrm{a}, *}$
}

\section{KEYWORDS}

- Total ankle replacement $\bullet$ Ankle alignment $\bullet$ Arthritic valgus ankle $\bullet$ Valgus deformity

- Realignment surgery for arthritic valgus ankle

- Total ankle replacement for arthritic valgus angle

\section{KEY POINTS}

- The ankle joint has highly congruent bony surfaces allowing for 3 articulations, and it is part of a biomechanical hindfoot complex.

- Ankle osteoarthritis $(\mathrm{OA})$ is a growing problem; approximately $1 \%$ of the world's adult population is affected by pain, dysfunction, and impaired mobility.

- Trauma is the primary cause of ankle $O A,{ }^{1,2}$ often resulting in varus or valgus deformities. Only $50 \%$ of all patients with end-stage ankle OA have normal hindfoot alignment.

\section{ARTHRITIC VALGUS ANKLE Ankle Alignment}

The alignment of the hindfoot can be divided into 3 anatomic aspects: supramalleolar, tibiotalar (orientation of the line of the tibiotalar joint), and inframalleolar. ${ }^{1-8}$ The medial distal tibial angle (MDTA) is used to quantify supramalleolar alignment. In a radiographic study ${ }^{9}$ it measured $92.4 \pm 3.1^{\circ}$ (range $88-100^{\circ}$ ) and in a cadaver study it measured $93.3 \pm 3.2^{\circ}$ (range $88-100^{\circ}$ ). ${ }^{10}$ The mortise view should be used for measurements of the MDTA because it depends on radiographic technique, specifically the length of the tibia visible in the radiograph. ${ }^{11}$ In general, reliable assessment of the inframalleolar alignment is much more difficult. Visual inspection of the hindfoot and clinical measurements with a goniometer are inaccurate..$^{8,12-14}$ The mortise view

\footnotetext{
The authors have nothing to disclose.

a Orthopaedic Department, University Hospital of Basel, University of Basel, Spitalstrasse 21, Basel CH-4031, Switzerland; b Harold K. Dunn Orthopaedic Research Laboratory, University Orthopaedic Center, University of Utah, 590 Wakara Way, Salt Lake City, UT 84108, USA

* Corresponding authors.

E-mail addresses: abarg@uhbs.ch; vvalderrabano@uhbs.ch
} 
should not be used for evaluation of the inframalleolar alignment because in most cases the heel is hard to identify because of overlap of the midfoot, and the heel has a false lateral position ( $20^{\circ}$ inner rotation of the foot and ankle). The Saltzman view is suggested for assessment of inframalleolar alignment. ${ }^{15}$ In our experience, the physiologic inframalleolar alignment should be neutral or $1^{\circ}$ to $2^{\circ}$ of varus ${ }^{7,8,16}$ and not $5^{\circ}$ to $7^{\circ}$ of valgus as reported in previous studies. ${ }^{15,17-19}$

\section{Development of Osteoarthritis in Valgus Ankle}

Valgus supramalleolar and/or inframalleolar deformities lead to an increase in pressure in the lateral part of the tibiotalar joint causing asymmetric lateral joint degeneration: distal tibial malunions, shortening fibula malunion, medial ankle ligament instability, hindfoot coalitios, posterior tibial tendon insufficiency, posttraumatic valgus sequelae of the hindfoot. Therefore, hindfoot malalignment has been identified as one of the most important risk factors of ankle osteoarthritis (OA) in numerous studies. ${ }^{20-27}$ Steffensmeier and colleagues ${ }^{28}$ analyzed the effects of medial and lateral displacement calcaneal osteotomies on tibiotalar joint contact stresses in cadavera. Lateral displacements unloaded the medial part of the tibiotalar joint whereas medial calcaneal displacements had the converse effect. ${ }^{28}$ Recently, Knupp and colleagues ${ }^{29}$ investigated changes in joint pressure and force transfer in cadaveric ankles with a supramalleolar deformity created by supramalleolar osteotomies. In specimens with an osteotomized fibula, valgus supramalleolar deformities led to a shift in force and peak pressure in the posterolateral direction. ${ }^{29}$

Valderrabano and colleagues ${ }^{1}$ evaluated different causes leading to ankle OA and compared the important clinical and radiologic variables among the different groups. The mean radiologic alignment in the coronal plane was $88.0^{\circ}$ (range 51-116 ${ }^{\circ}$ : 148 ankles (37\%) had normal alignment, 225 ankles (55\%) had varus alignment, and 33 ankles $(8 \%)$ had valgus alignment. This distribution was similar in all 3 groups: patients with posttraumatic, secondary, and primary OA. ${ }^{1}$ Similar results were observed by Chou and colleagues ${ }^{30}$ with $13 \%$ of all patients with primary ankle OA presenting with planovalgus deformity.

Medial ligamental instability has been shown to be an important risk factor for pathogenesis of ankle OA. ${ }^{31,32}$ Clarke and colleagues $^{33}$ developed a cadaveric ankle model and showed that sectioning of the deltoid ligament, regardless of fibular displacement, created up to $20^{\circ}$ decrease in the contact area of the ankle joint. Harper ${ }^{34}$ performed an anatomic study to evaluate the functions of the deltoid ligament, and showed that sectioning the superficial deltoid ligament did not result in increased anterior translation or lateral shift of the talus, whereas sectioning of the deep deltoid ligament did result in significant lateral shift and anterior translation of the talus. ${ }^{34}$ Earll and colleagues ${ }^{35}$ used 15 normal cadaveric lower extremities and observed the most significant changes in tibiotalar pressure after sectioning of the tibiocalcaneal fibers of the superficial deltoid ligament complex. ${ }^{35}$ Michelson and colleagues $^{36}$ demonstrated that disruption of the deep deltoid ligament significantly increased the internal rotation of the foot.

\section{Morthophological Type of Arthritic Valgus Ankle}

Arthritic valgus ankles can be divided into 2 different morphologic types. The first type includes severe pes planovalgus deformity with insufficiency of the medial ligaments and advanced posterior tibial tendon insufficiency. ${ }^{37-40}$ In the second type, osseous deformities are the primary factors. Osseous deformities and/or defects may result from malunion after fibular fractures or fractures of distal tibia (especially after intraarticular tibial plafond fractures). 


\section{TREATMENT OPTIONS IN THE ARTHRITIC VALGUS ANKLE}

Patients with an arthritic valgus ankle should be individually assessed and all concomitant pathologic conditions should be considered and addressed if necessary. Examples include: deltoid ligament insufficiency, dysfunction of the posterior tibial tendon, contracted heel cord, osseous deformities and/or defects of the distal tibia, shortening and/or deformity of the fibula, and inframalleolar deformities. Given the wide range of potential concomitant pathologic conditions, a generic approach in these patients may result in frequent clinical failure. ${ }^{37}$

\section{Realignment Surgery for the Arthritic Valgus Ankle}

In patients with arthritic valgus ankles, conservative treatment should be attempted first. Conservative treatment includes nonsteroidal antirheumatic therapy, shoe modifications with special insoles, physiotherapy, and semi-rigid orthoses. ${ }^{42}$ The decision to plan realignment surgery should not be postponed too long because the development of degenerative changes is continuous and may proceed quickly.

The main indication for realignment surgery is lateral valgus ankle joint $O A .{ }^{21,43}$ Cartilage of more than half of tibiotalar joint surface should be preserved. This may be assessed preoperatively by magnetic resonance imaging ${ }^{44}$ and/or single photon emission-computed tomography (SPECT). ${ }^{45,46}$ Furthermore, before realignment surgery, we recommend ankle arthroscopy or arthrotomy to assess the degree and localization of cartilage damage and ligamental instability. ${ }^{21}$ We also recommend evaluation of cartilage degeneration according to the Outerbridge classification: grade 0 , no cartilage damage; grade 1, cartilage softening; grade 2, cartilage damage with stripping of superficial cartilage layers; grade 3, deep cartilage ulceration without visible subchondral bone; grade 4 , visible subchondral bone. ${ }^{47}$

Realignment surgery should not be performed in ${ }^{21}$

- patients in poor general health (especially patients who are unable to perform nonweight bearing exercises during the initial postoperative rehabilitation)

- patients with systemic joint disease

- patients with nonmanageable insufficiency of the deltoid ligament

The surgical realignment technique for arthritic valgus ankle has been described in detail previously. ${ }^{21}$ The main surgery includes a medial-closing wedge osteotomy performed in the distal tibial metaphysis (Fig. 1). The aim of the surgery should be a final $2^{\circ}$ to $5^{\circ}$ varus orientation of the distal tibial joint. ${ }^{21,48-50}$ In most cases, additional osseous and ligamental surgical procedures are necessary to achieve a wellbalanced and stable hindfoot with restored physiologic biomechanics. Additional corrective surgeries should be performed depending on the stage and origin of the valgus deformity. ${ }^{49}$ Patients with stage I deformity present with collapse of the lateral compartment of the tibial plafond and/or lateral malleolar gutter. In patients with stage I deformity with fibular malunion, a corrective lengthening osteotomy of the fibula should be performed. In patients with stage II deformity, lateral ankle joint degeneration is observed in combination with significant inframalleolar valgus alignment (heel valgus). In such cases, a medial sliding osteotomy ${ }^{51,52}$ should be performed after correction of the tibiotalar joint deformity by supramalleolar osteotomy. In general, the heel-ground contact point should be shifted medially until a final position of 0 to $5 \mathrm{~mm}$ medial to the loading axis is achieved (Saltzman view). Stage III valgus deformity usually develops as a result of progressive flat foot deformity (eg, patients with stage $\mathrm{III}^{53}$ or IV ${ }^{38,54}$ dysfunction of the posterior tibial tendon). In these patients, inframalleolar deformity should be addressed by performing lateral calcaneal lengthening 

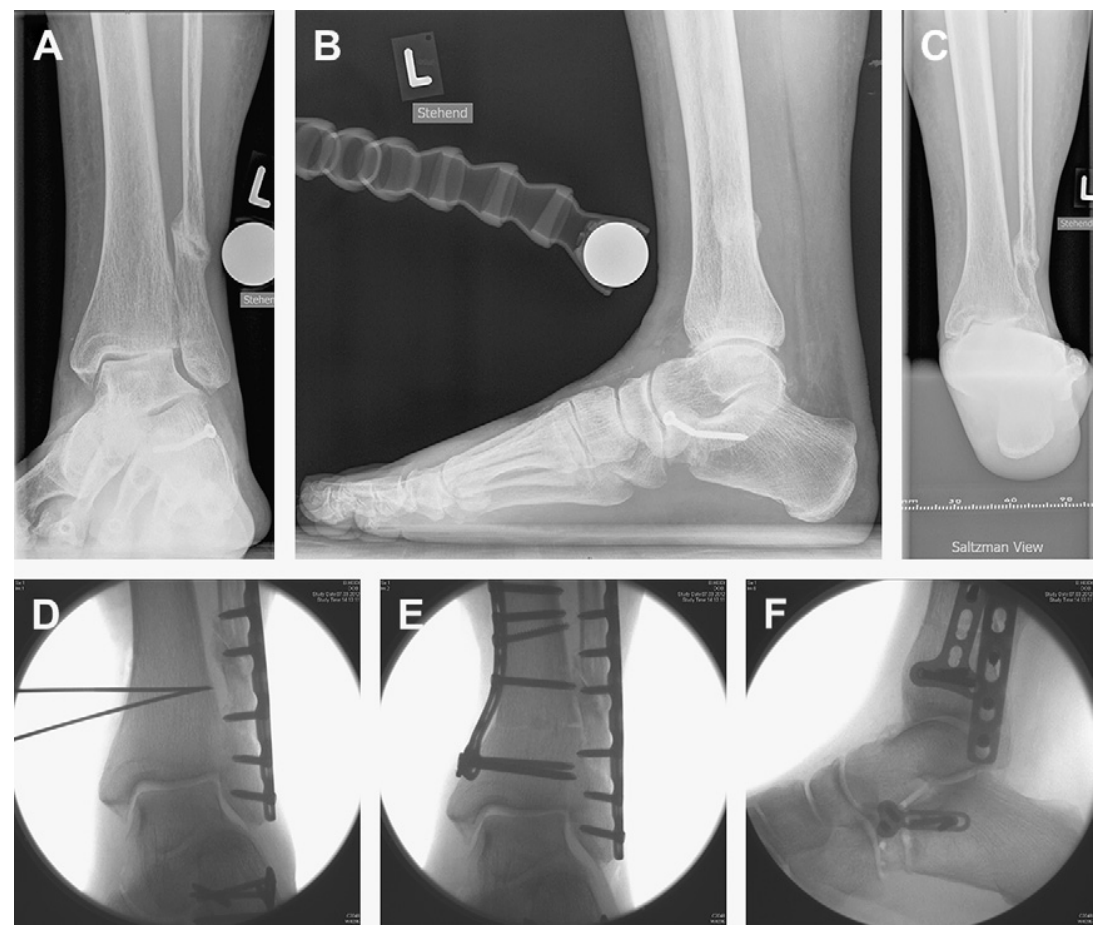

Fig. 1. A 58-year-old woman with progressive valgus malalignment of the hindfoot. (A) Anteroposterior radiograph shows the medial tilting of the talus with consecutive collapse of the lateral compartment of the tibiotalar joint. Significant shortening of the fibula is observed due to nonunion of a fibula stress fracture. $(B)$ Lateral view shows nonunion of a previous attempt lengthening osteotomy of the calcaneus with a broken screw. (C) Saltzman view shows valgus malposition of the heel. $(D)$ First, lengthening of the fibula has been performed with debridement of the nonunion area and stabilization with a plate. Also nonunion of the calcaneus osteotomy was debrided and refixed using a plate. Planning the supramalleolar medial-closing wedge osteotomy using $2 \mathrm{~K}$-wires. $(E, F)$ Physiologic alignment of the hindfoot with appropriate talus position within the mortise.

osteotomy to correct valgus abductus. ${ }^{55}$ In some patients, additional forefoot correction surgery (eg, flexion osteotomy of the first metatarsal or medial cuneiform ${ }^{56}$ ) should be performed. Medial soft tissue procedures (posterior tibial tendon augmentation, reconstruction of medial ligaments) should be performed to achieve postoperative ligamental stability. In patients with fixed rigid pes planovalgus deformity, medial column procedures $^{57,58}$ or triple arthrodesis ${ }^{59,60}$ should be performed to restore the physiologic medial arch of the foot.

\section{Pitfalls of Realignment Surgery for Arthritic Valgus Ankle}

In patients with undercorrected valgus deformity, the degenerative changes of the lateral part of the tibiotalar joint may progress. Therefore, realignment surgery should be repeated. Overcorrection after supramalleolar osteotomy is rare. ${ }^{21}$ In patients with radiological delay or nonunion, immobilization in a stable walker or cast should be extended for 3 months postoperatively. We recommend computed tomography or SPECT scans to assess the status of the union 6 months after the primary surgery. In patients with symptomatic nonunion, internal fixation with grafting should be 
performed. The restricted range of motion of the realigned ankle should be treated first with intensive physiotherapy including stretching of triceps surae. In patients with chronic unmanageable triceps surae contracture, a percutaneous release may be performed. In patients with restriction of range of motion caused by osteophytes, open or arthroscopic debridement can be performed. In patients with progressive development of tibiotalar OA, joint-sacrificing procedures (ankle fusion or total ankle replacement [TAR]) should be discussed.

\section{TAR in Patients with Valgus Deformity}

Joint-sacrificing treatments include TAR (Fig. 2) and ankle fusion. They should be performed when joint-preserving procedures (eg, corrective osteotomies and/or ligament
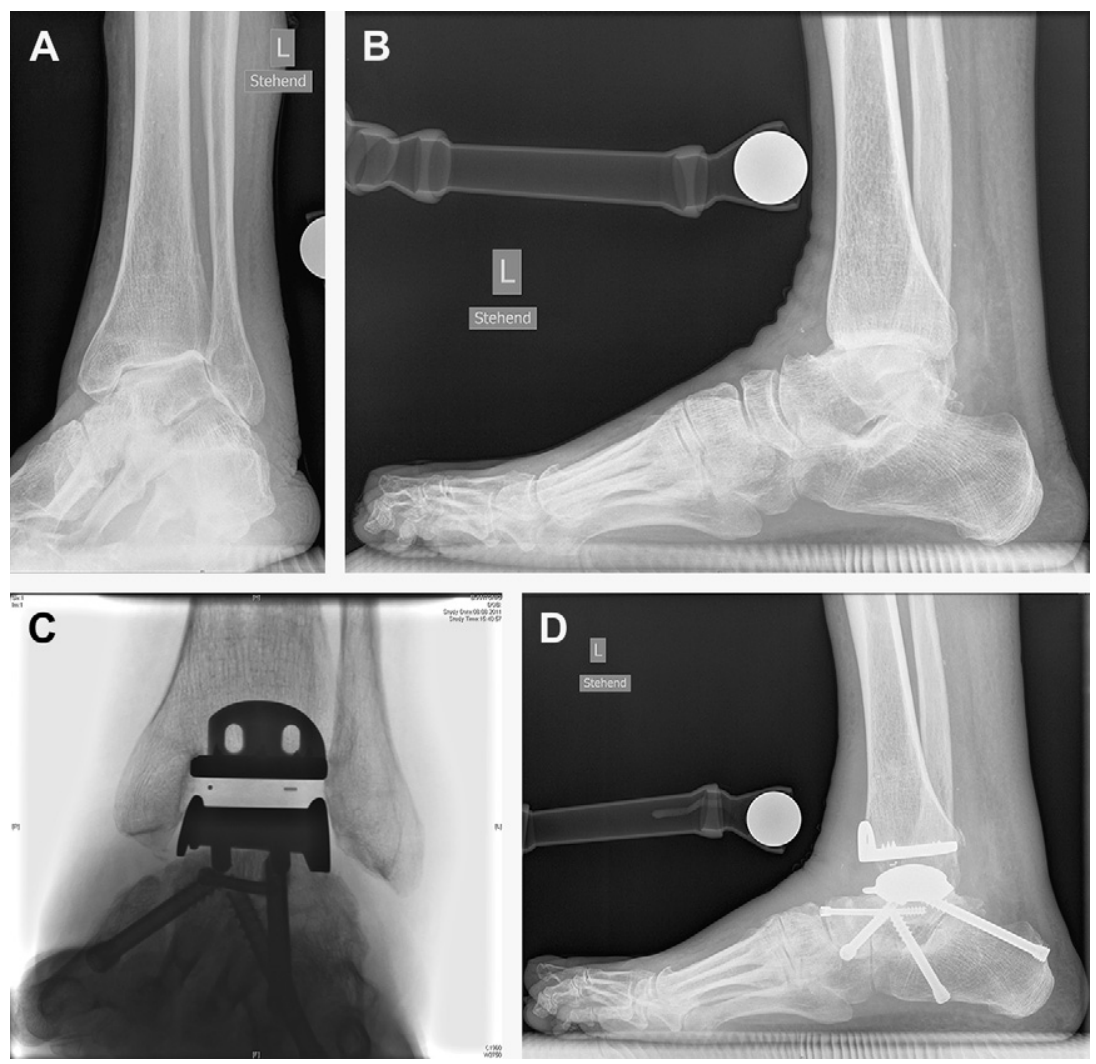

Fig. 2. An 82-year-old man with progressive valgus arthritic ankle and stage IV posterior tibial tendon dysfunction. The symptoms started 4 years previously and were progressive. The patient presented with significant impairment of mobility: maximal walking distance ca $100 \mathrm{~m}$. (A) Anteroposterior radiograph shows a valgus arthritic ankle with subfibular impingement and lateralization of the heel. $(B)$ Lateral view shows a collapsed tibiotalar joint line and degenerative changes of the subtalar and talonavicular joints. $(C, D)$ Postoperative radiographs show appropriate alignment of prosthesis components. The hindfoot alignment was restored by modified triple arthrodesis (subtalar and talonavicular arthrodesis). (Data from De Wachter J, Knupp M, Hintermann B. Double-hindfoot arthrodesis through a single medial approach. Techniques in Foot \& Ankle Surgery 2007;6:237-42; and Knupp M, Stufkens SA, Hintermann B. Triple arthrodesis. Foot Ankle Clin 2011;16:61-7.) 
reconstruction) have failed. Ankle fusion may result in pain relief, at least in the short term, ${ }^{61,62}$ however, mid-term and long-term problems include impaired mobility, difficulty walking on uneven surfaces, and difficulty running. ${ }^{63-65}$ Increased load in the adjacent joints may lead to degenerative changes and painful $O A .{ }^{61,64}$ Therefore, ankle fusion is no longer the gold standard therapy in patients with end-stage ankle OA. ${ }^{66}$

For TAR, we use the HINTEGRA prosthesis, a nonconstrained 3-component system. ${ }^{67-70}$ A standardized surgical technique is used for implantation of the prosthesis components (see article by Barg and colleagues in this issue). In patients with valgus deformity of less than $10^{\circ}$, correction of the tibiotalar joint can be achieved by modification of bone cut. In patients with valgus deformity of more than $10^{\circ}$, additional surgeries should be performed depending on the localization and degree of the valgus deformity (Fig. 3):

- supramalleolar osteotomy (eg, medial-closing wedge osteotomy) ${ }^{21,49,71,72}$

- lengthening and (if necessary) rotational osteotomy of the distal fibula ${ }^{73,74}$

- corrective osteotomies of the calcaneus: medial displacement calcaneal ostoeotomy ${ }^{51,52}$ or lateral column lengthening osteotomy of the calcaneus ${ }^{49,75-77}$

- reconstruction and repair of the medial ligaments ${ }^{78,79}$

- corrective subtalar fusion or triple arthrodesis ${ }^{59,60}$

In patients with severe hindfoot valgus malalignment due to significant valgus deformity and defects of the tibial plafond, we suggest the following chronologic sequence of surgical procedures. First, the supramalleolar deformity should be corrected by supramalleolar osteotomy followed by TAR. In patients with a remaining valgus position of the heel, calcaneal osteotomy or subtalar or triple arthrodesis (especially in patients with degenerative changes of the subtalar joint) should be performed. Ligamental instability should then be addressed by reconstruction and repair of the ligaments.

In patients with severe hindfoot valgus due to pes planovalgus deformity with insufficiency of the medial ligaments and/or posterior tibial tendon, we first suggest corrective subtalar or triple arthrodesis before implantation of prosthesis components. At the end of the surgery, ligamental reconstruction and fibula-lengthening osteotomy should be performed if necessary.

In patients with moderate hindfoot valgus, we implant prosthesis components first and then address the inframalleolar valgus malalignment by calcaneal osteotomy or

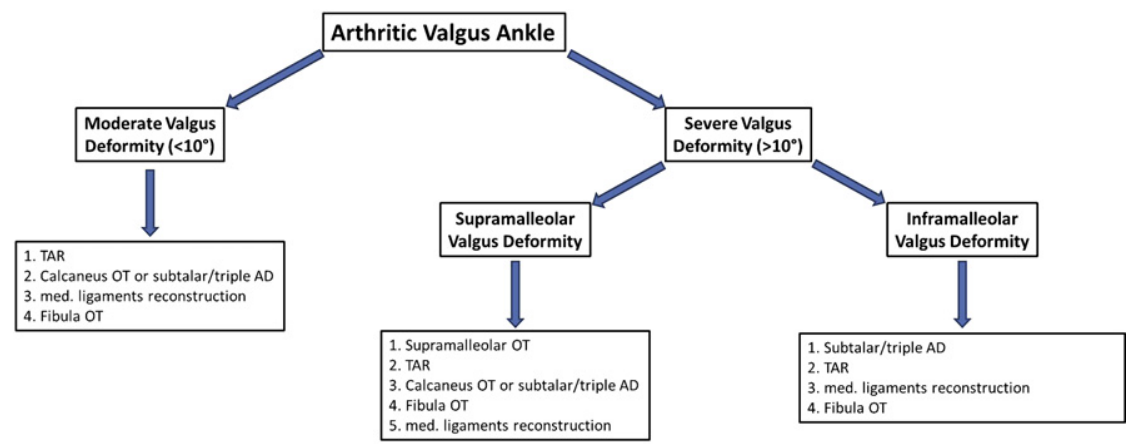

Fig. 3. Treatment strategy used for TAR in patients with preoperative valgus deformity of the hindfoot depends on the degree of the valgus deformity. AD, arthrodesis; med., medial; OT, osteotomy. 
corrective subtalar or triple arthrodesis (patients with degenerative changes of the subtalar joint). In these patients, ligamental reconstruction and fibula-lengthening osteotomy should also be performed if necessary.

\section{Pitfalls of TAR in Patients with Valgus Deformity}

TAR is gaining acceptance among foot and ankle surgeons as an alternative treatment in patients with end-stage ankle OA. However, this procedure remains technically demanding and has a steep learning curve.$^{80-82}$ Correct positioning of the prosthesis components is one of the most demanding steps, ${ }^{80,83}$ especially in patients with preoperative valgus or varus deformity. Malposition of the prosthesis components has biomechanical consequences, as shown in numerous cadaveric studies. ${ }^{84-86}$ Recently, a clinical study showed that patients with neutrally aligned prosthesis components had the best clinical outcomes including range of motion and pain relief. ${ }^{87}$ When the preoperative deformity was not sufficiently addressed, patients developed medial pain syndrome requiring revision surgery. ${ }^{88}$ Furthermore, the patients who underwent TAR with a malaligned hindfoot were more likely to develop edge loading and are at higher risk for prosthesis failure. ${ }^{14,89-92}$

\section{LITERATURE REVIEW: TAR EXPERIENCE IN PATIENTS WITH VALGUS DEFORMITY}

The first clinical report addressing the feasibility and clinical outcomes of TAR recognized preoperative varus or valgus deformity as a possible source of prosthesis failure. Newton ${ }^{93,94}$ performed 50 TAR procedures using the Newton Ankle Implant (a nonconstrained cemented prosthesis including high density polyethylene tibial and Vitallium talar components). Valgus or varus deformity of the talus greater than $20^{\circ}$ was noted as an absolute contraindication for TAR. ${ }^{93,94}$ In a later study, ${ }^{95}$ Newton stated that although valgus or varus deformity of up to $15^{\circ}$ could be corrected initially, the coronal deformity usually recurred. All ankles replaced with a talar tilt of more than $20^{\circ}$ failed during the follow-up. ${ }^{95}$ Kirkup ${ }^{96}$ observed that severe valgus or varus deformity was common in many patients with rheumatoid OA. The author recognized that these deformities could not be corrected by cutting wedges, therefore, preoperative coronal deformity greater than $30^{\circ}$ was a contraindication for TAR. ${ }^{96}$ Stauffer and Segal ${ }^{97}$ performed 102 TAR procedures using the Mayo Total Ankle, which is a highly congruent 2-component design including a polyethylene tibial component and cement fixation. The procedure was not performed in patients with preoperative coronal deformity (varus or valgus) of more than $20^{\circ} .{ }^{97}$

Pyevich and colleagues ${ }^{98}$ analyzed the mid-term results of 100 consecutive Agility TAR procedures performed between 1984 and 1993 with a mean follow-up of 5 years. Preoperative valgus or varus malalignment was corrected using an external fixator. Mclff and colleagues ${ }^{99}$ and Vienne and Nothdurft ${ }^{100}$ suggested the intraoperative correction of varus or valgus deformity using the external fixator with the Agility TAR. Pyevich and colleagues ${ }^{98}$ observed that the position of the tibial component had a significant influence on the outcome. Patients with tibial components placed in more than $4^{\circ}$ valgus had significantly more postoperative pain $(P<.05)$ than the patients with neutrally aligned prosthesis components.

Saltzman ${ }^{101}$ reviewed the state of the art in using TAR in 2000 . He recognized that preoperative varus or valgus deformity, which was not sufficiently addressed during the TAR procedure, may lead to loading that accelerates the rate of polyethylene wear. ${ }^{101}$

Greisberg and Hansen ${ }^{102,103}$ presented their strategies on how to address the associated deformities in patients with TAR. In patients with valgus foot due to medial 
collapse, the medial column should be restored, which may also regain the appropriate tension of the medial ligaments. The investigators suggest placing the tibial and talar components in a slightly lateral position. If the valgus malalignment of the hindfoot persists, a medial sliding osteotomy of the calcaneus should be performed. In patients with advanced flat foot deformity, a triple arthrodesis in addition to medial column stabilization may be performed to achieve proper alignment in the long term. The investigators stated that patients with persistent misalignment of the replaced ankle may have a higher risk of prosthesis failure. ${ }^{102,103}$

Conti and Wong ${ }^{90,91}$ reviewed the possible complications of TAR. Varus or valgus malpositioning of the prosthesis components was a possible source of TAR failure. They stated that valgus positioning of the prosthesis component may be better tolerated that varus positioning. However, they recommended corrective osteotomy for supramalleolar deformity of more than $10^{\circ}$ and cutting jig adjustment in ankles with any deformities of the distal tibial articular surface..$^{90,91}$

Stamatis and Myerson ${ }^{104}$ described how to avoid specific complications of TAR. They observed different pathologic conditions in valgus arthritic ankles including contracted lateral ligaments and insufficient medial ligaments, valgus heel, shortening and deformities of the fibula causing chronic impingement, and/or rupture of the spring ligament and posterior tibial tendon. The correction of the valgus deformity included several osseous and ligament procedures. ${ }^{104}$

Wood and Deakin ${ }^{105}$ reviewed the results of 200 cementless, mobile-bearing Scandinavian TAR (STAR) procedures performed between 1993 and 2000. Preoperatively, 39 ankles had a significant coronal deformity of more than $15^{\circ}(17$ ankles with varus and 22 ankles with valgus deformity). Seven of these 39 ankles (18\%) developed edge loading, whereas only 2 of the 161 ankles with neutral alignment $(1 \%)$ had comparable problems. Of the 9 patients with edge loading 3 had additional surgery to improve realignment and stability of the hindfoot and 3 ankles ended up in conversion to ankle fusion. Therefore, the investigators stated that preoperative varus or valgus deformity of the talus of more than $10^{\circ}$ was a relative contraindication for TAR. ${ }^{105}$ Similar findings were observed in a later study including the same 200 STAR procedures. ${ }^{106}$ Wood and colleagues $^{107}$ performed a review and addressed the outcomes of currently available TAR designs. The investigators found that the failure rate was lower in ankles that were well aligned than in ankles with more than $15^{\circ}$ of valgus or varus preoperative deformity. ${ }^{107}$

Assal and colleagues ${ }^{108}$ presented a case report describing fracture of the polyethylene component in a patient who underwent Agility TAR caused by varus malalignment of the talar component. The investigators stated that uncorrected foot and hindfoot deformities may induce significant valgus or varus forces resulting in pathologic polyethylene wear patterns. Therefore, especially in patients who undergo Agility TAR, normal alignment is important because the Agility TAR system has little intrinsic stability. ${ }^{108}$

Hintermann and Valderrabano ${ }^{69}$ reviewed the use of TAR in 2003. In earlier clinical studies, patients with significant preoperative varus or valgus deformities were excluded from TAR, and ankle fusion was performed. The investigators stated that, as long the deformities could be corrected before or during the TAR procedure, they were not a contraindication for TAR. ${ }^{69}$

Takakura and colleagues ${ }^{109}$ reviewed 160 TARs performed between 1975 and 2000 using a TNK ceramic prosthesis, which underwent 3 generations of development. The investigators suggested that TAR should not be used in patients with varus or valgus deformities of the tibial articular surface exceeding $15^{\circ}$, because of observed loosening and subsidence of the prosthesis in the early postoperative period. ${ }^{109,110}$ 
Greisberg and colleagues ${ }^{111}$ addressed the importance of hindfoot alignment in patients undergoing TAR and described how to achieve a well-balanced hindfoot. Two different reasons for valgus malalignment in the ankle were described: posttraumatic arthritic ankle with loss of bone from the lateral plafond and advanced flatfoot with insufficient medial ligaments. The investigators recommended medial ligament reconstruction and, if necessary, restoration of the medial column. For valgus ankles, the bone cuts were not performed too close to the medial malleolus. After implantation of the final prosthesis components, the position of the hindfoot and the heel were checked and if the ankle remained in valgus, a medial sliding calcaneal osteotomy was performed. ${ }^{111}$

Haskell and Mann ${ }^{92}$ presented short-term results of 86 patients who underwent STAR with a mean follow-up of 2 years. Thirty-five of 86 patients had a preoperative coronal plane deformity of more than $10^{\circ}(25$ patients with varus deformity and 10 patients with valgus deformity). All patients were divided into 4 groups: varus congruent, valgus congruent, varus incongruent, and valgus incongruent. In ankles with talar and tibial deformities, talar and tibial alignment improved toward a neutral weight-bearing axis postoperatively. The alignment remained constant during the subsequent 2 years. Eight of 34 patients developed progressive edge loading requiring 4 additional procedures. The patients with preoperative incongruent joints were 10 times more likely to develop postoperative edge loading. ${ }^{92}$

Kofoed ${ }^{112}$ described a special sculpting technique on the talus that allows intraoperative correction of varus or valgus ankle deformity of more than $45^{\circ}$. This technique included cutting 1- to 2-mm slices off the talus facets and the talar dome, followed by rotation of the entire hindfoot inside the ankle mortise until normal hindfoot alignment was achieved. The investigators presented a case of a patient with preoperative valgus deformity of about $50^{\circ}$, with only a slight postoperative valgus alignment of the hindfoot. ${ }^{112}$

Doets and colleagues ${ }^{113}$ performed a prospective single-center study including 19 low contact stress mobile-bearing TARs and 74 Buechel-Pappas TARs. The 8-year survivorship for both prostheses, with revision or conversion to an arthrodesis for any reason as the end point, was $85 \%$ (95\% Cl 73\%-93\%). However, the same survivorship in 17 ankles with a preoperative varus or valgus deformity of more than $10^{\circ}$ was significantly lower $(P=.03)$ at $48 \%(95 \% \mathrm{Cl} 6 \%-90 \%)$, whereas survivorship in ankles with a neutral preoperative alignment was $90 \%(95 \% \mathrm{Cl} 82 \%-98 \%)$. In 2 ankles with preexisting valgus deformity, a medial malleolar fracture occurred intraoperatively with nonunion in the further course. Both ankles also developed a stress fracture of the lateral malleolus resulting in nonmanageable valgus instability requiring ankle fusion. Therefore, the investigators defined preoperative valgus or varus deformity of more than $10^{\circ}$ as an absolute contraindication for TAR. The investigators suggested that corrective surgery (eg, triple arthrodesis) should be performed before TAR to restore normal biomechanics and alignment of the hindfoot. ${ }^{113}$

Henricson and Ågren ${ }^{114}$ performed 196 second-generation TARs in 186 patients with a mean follow-up of 4 years: 109 STAR, 62 Buechel-Pappas, and 22 AES (Ankle Evolutive System; Transystem, France) ankles. All ankles were divided into 3 groups: (1) normal hindfoot alignment (normal value was set to $5^{\circ}$ valgus) $n=92$; (2) varus alignment (mean $9.6^{\circ}$, range $5-30^{\circ}$ ) $\mathrm{n}=55$; (3) valgus alignment (mean $11^{\circ}$, range $\left.5-30^{\circ}\right) \mathrm{n}=46$. The preoperative valgus malalignment was neutralized in 20 ankles, 1 overcorrected in slight varus, and 23 ankles stayed in a valgus position (mean $7.6^{\circ}$, range $5-15^{\circ}$ ). The overall revision rate was $21 \%$. The revision rate was $31 \%$ in the preoperative varus group and $17 \%$ in the valgus and neutral groups, respectively. Therefore, the investigators stated that additional surgeries should be performed to 
achieve neutral alignment and TAR should be limited only to experienced foot and ankle surgeons. ${ }^{114}$

Coetzee ${ }^{89}$ presented his strategies on how to perform TAR in patients with varus or valgus deformities. He identified that most valgus deformities are secondary to chronic posterior tibial tendon dysfunction. A lateral release could be done to get the talus in the correct position in the mortise. A primary deltoid repair can be performed; however, it is never strong enough. The following corrective procedures were suggested: posterior tibial tendon repair with augmentation of the flexor digitorum longus tendon, gastrocnemius slide, and stabilization of the medial ray. In patients with severe and rigid valgus deformities, a triple arthrodesis was performed to achieve long-term stability. The author suggested $15^{\circ}$ of varus or valgus ligamentous instability as the arbitrary cut-off point and $10^{\circ}$ as the hard cut-off point for performing ankle fusion. ${ }^{89}$

Bluman and Chiodo ${ }^{37}$ described the anatomy and biomechanics of valgus arthritic ankles and presented different therapeutic strategies. In patients with preoperative coronal deformities of more than $15^{\circ}$, there was a higher risk of mechanical failure. However, in valgus arthritic ankles, all concomitant deformities (proximal and distal to the tibiotalar joint) should be sufficiently addressed. ${ }^{37}$

Wood and colleagues ${ }^{14}$ performed a randomized, prospective, single-center study including 200 TARs to compare Buechel-Pappas and STAR implants with a minimum follow-up of 3 years. The 6 -year survivorship was comparable $(P=.09)$ in both groups: $79 \%$ (95\% Cl 63.4\%-88.5\%) and 95\% (95\% Cl 87.2\%-98.1\%) in the Buechel-Pappas and STAR groups, respectively. However, the investigators observed a significantly higher $(P=.02)$ incidence of prosthesis failure in ankles with preoperative varus or valgus deformity, especially when the deformity was greater than $15^{\circ}$, resulting in a predicted failure rate at 6 years exceeding $10 \%$ for the STAR prosthesis and $25 \%$ for the Buechel-Pappas prosthesis. When the preoperative deformity was $15^{\circ}$ or less, the estimated 6-year survivorship was $86.7 \%$ for the Buechel-Pappas group and $95.5 \%$ for the STAR group. ${ }^{14}$ Wood and colleagues ${ }^{115}$ also shared their experience of TAR in patients with rheumatoid ankle OA. Nearly $50 \%$ of all patients with rheumatoid $\mathrm{OA}$ requiring either fusion or TAR presented with valgus deformity. In patients who underwent TAR, the heel should be well aligned under the tibia, which can be achieved by hindfoot fusion, as a 1-stage procedure, or 6 or 12 weeks before the ankle replacement. ${ }^{115}$ In some patients, the valgus deformity had been corrected without ligamental release, but an alarming gap on the lateral side between the malleolus and prosthesis component was seen. ${ }^{116}$

Karantana and colleagues ${ }^{117}$ retrospectively reviewed 45 patients with 52 TARs using the STAR prosthesis with a minimum follow-up of 5 years. Thirteen ankles $(27 \%)$ had a preoperative coronal deformity of more than $10^{\circ}$ (range $11-25^{\circ}$ ); most of them were in preoperative varus. The investigators believed that the preoperative hindfoot deformity was not an absolute contraindication for TAR, as long the deformity was manageable by additional realignment procedures including soft tissue releases, ligament reconstructions, calcaneal osteotomies, and corrective subtalar fusion. ${ }^{117}$

Wood and colleagues ${ }^{118}$ reported short-term clinical and radiological results of a prospective case series including 100 Mobility TARs with a minimum follow-up of 3 years. There were 15 ankles with a preoperative coronal deformity between $16^{\circ}$ and $20^{\circ}$. A varus or valgus deformity was observed in 33 (in 17 of these it was more than $10^{\circ}$ ) and in 29 (in 13 of these it was more than $10^{\circ}$ ) ankles, respectively. Postoperatively, there were 5 cases of edge loading of the mobile insert due to varus or valgus deformity. Of 5 ankles requiring revision surgery, 4 had significant preoperative coronal deformity: 3 patients with valgus deformity $\left(11^{\circ}, 12^{\circ}\right.$, and $\left.15^{\circ}\right)$ and 1 patient 
with varus deformity $\left(19^{\circ}\right)$. Therefore, the investigators do not undertake TAR in patients with preoperative valgus or varus deformity of more than $20^{\circ}$. In these cases, the investigators recommend ankle fusion. ${ }^{118}$

Ellis and DeOrio ${ }^{119}$ described the surgical technique using the INBONE prosthesis in detail. The investigators described how to correct slight varus or valgus deformity intraoperatively using a laminar spreader with teeth; the desired position of the talus should be $5^{\circ}$ of valgus. However, the investigators stated that valgus deformity is more difficult to correct using this technique. ${ }^{119,120}$

Skyttä and colleagues ${ }^{121}$ presented the survivorship analysis of the Finnish Arthroplasty Register included 515 TARs performed between 1982 and 2006. Nine different TAR prostheses were used. The most common TAR types were AES, STAR, ICLH, and HINTEGRA prostheses with 298, 217, 32, and 11 cases, respectively. The proportion of revisions done for instability in primary TAR was 39\%. One of the reasons for prosthesis failure was preoperative valgus or varus deformity with insufficient ligaments. ${ }^{121}$

Morgan and colleagues ${ }^{122}$ presented the outcomes in 38 consecutive patients who underwent TAR using the AES ankle with a minimum follow-up of 4 years. Twentyeight patients had normal hindfoot alignment preoperatively, 10 patients had a valgus alignment ranging from $7^{\circ}$ to $30^{\circ}$, and 7 patients had a varus alignment ranging from $4^{\circ}$ to $23^{\circ}$. Postoperatively, 10 patients presented with edge loading; 5 and 2 of them had preoperative varus and valgus alignment, respectively. ${ }^{122}$

$\mathrm{Kim}$ and colleagues ${ }^{123}$ reported the clinical and radiological outcomes of TAR in association with hindfoot fusion. Three ankles $(5 \%)$ in the hindfoot fusion group and 10 ankles $(3.5 \%)$ in the control group had preoperative coronal deformity of more than $15^{\circ}$. Significant valgus or varus deformity was not associated with a worse functional outcome or higher failure rate. ${ }^{123}$

Bonasia and colleagues ${ }^{124}$ presented a review regarding indications for TAR and their surgical techniques. For small minimal distal tibial deformities less than $10^{\circ}$, realignment can be achieved by modification of the tibial cut. For more severe deformities, a dome or wedge osteotomy should be performed before TAR. ${ }^{124}$

Bonnin and colleagues ${ }^{125}$ retrospectively reviewed 98 TARs performed in 97 ankles between 1997 and 2000 using the Salto prosthesis. The investigators did not consider substantial preoperative varus or valgus deformity as a contraindication for TAR. However, all hindfoot deformities were corrected as a first step with an associated procedure (eg, triple arthrodesis). ${ }^{125}$ In some patients with preoperative valgus deformity, a special cemented lateral malleolar component was implanted to normalize load transfer in this patient cohort. ${ }^{126}$

Recently, Trincat and colleagues ${ }^{127}$ presented their results of using TAR in patients with coronal plane deformities. Of a total of 131 TARs, 21 TARs (16 AES ankles, 4 Salto ankles, and $1 \mathrm{New}$-Jersey ankle) were performed in ankles with preoperative coronal deformities of more than $10^{\circ}$. There were 4 congruent and 2 incongruent valgus ankles. The following additional 1-stage surgeries were performed to achieve osseous and ligamental balancing: lateral malleolus lowering (2), Achilles tendon lengthening (4), reconstruction of medial ligaments (1), and triple arthrodesis (1). For congruent valgus ankles, surgery resulted in significant improvement in overall alignment from $14.7 \pm$ $2.5^{\circ}$ to $0 \pm 2.5^{\circ}$. There were no complications or failures in this subgroup. In preoperative incongruent valgus ankles, improvement in overall alignment from $19 \pm 5.5^{\circ}$ to $2 \pm 4.2^{\circ}$ was observed. Failure occurred in 1 patient who presented with a $23^{\circ}$ deformity caused by a bimalleolar fracture with insufficiency of the medial ligaments and posterior tibial tendon dysfunction. In conclusion, the short-term results of TAR in patients with preoperative coronal deformities of more than $10^{\circ}$ are comparable to those observed in patients with no deformities. However, several associated procedures were necessary 
to address the concomitant instabilities and deformities. Residual defects may compromise the longevity of prosthesis components and warrant further correction. ${ }^{127}$

\section{SUMMARY}

A clinically and radiologically well-aligned hindfoot and proper position of prosthesis components are the keys to long-term prosthesis stability and reliable functional outcomes in patients who undergo TAR. In patients with preoperative coronal deformities (valgus or varus), alignment and biomechanics should be restored. Our clinic typically strives to obtain a medial distal tibial angle of $90^{\circ}$ and neutral inframalleolar alignment (as assessed using the Saltzman view). A moderate preoperative valgus deformity of less than $10^{\circ}$ can be corrected intraoperatively by modification of bone cuts. In other patients, the deformity should be accurately corrected on the supramalleolar and/or inframalleolar levels before TAR. In patients with ligamental instability, reconstruction surgery should be performed to achieve a stable hindfoot.

\section{REFERENCES}

1. Valderrabano V, Horisberger M, Russell I, et al. Etiology of ankle osteoarthritis. Clin Orthop Relat Res 2009;467:1800-6.

2. Saltzman CL, Salamon ML, Blanchard GM, et al. Epidemiology of ankle arthritis: report of a consecutive series of 639 patients from a tertiary orthopaedic center. lowa Orthop J 2005;25:44-6.

3. Knupp M, Valderrabano V, Hintermann B. Anatomical and biomechanical aspects of total ankle replacement. Orthopade 2006;35:489-94 [in German].

4. Kitaoka HB, Luo ZP, An KN. Three-dimensional analysis of normal ankle and foot mobility. Am J Sports Med 1997;25:238-42.

5. Glazebrook M, Daniels T, Younger A, et al. Comparison of health-related quality of life between patients with end-stage ankle and hip arthrosis. J Bone Joint Surg Am 2008;90:499-505.

6. Horisberger M, Valderrabano V, Hintermann B. Posttraumatic ankle osteoarthritis after ankle-related fractures. J Orthop Trauma 2009;23:60-7.

7. Frigg A, Nigg B, Davis E, et al. Does alignment in the hindfoot radiograph influence dynamic foot-floor pressures in ankle and tibiotalocalcaneal fusion? Clin Orthop Relat Res 2010;468:3362-70.

8. Frigg A, Nigg B, Hinz L, et al. Clinical relevance of hindfoot alignment view in total ankle replacement. Foot Ankle Int 2010;31:871-9.

9. Knupp M, Ledermann $H$, Magerkurth $O$, et al. The surgical tibiotalar angle: a radiologic study. Foot Ankle Int 2005;26:713-6.

10. Inman VT. The joints of the ankle. Baltimore (MD): Williams \& Wilkins; 1976.

11. Stufkens SA, Barg A, Bolliger L, et al. Measurement of the medial distal tibial angle. Foot Ankle Int 2011;32:288-93.

12. Backer $\mathrm{M}$, Kofoed $\mathrm{H}$. Passive ankle mobility. Clinical measurement compared with radiography. J Bone Joint Surg Br 1989;71:696-8.

13. Buck P, Morrey BF, Chao EY. The optimum position of arthrodesis of the ankle. A gait study of the knee and ankle. J Bone Joint Surg Am 1987;69:1052-62.

14. Wood PL, Sutton C, Mishra V, et al. A randomised, controlled trial of two mobilebearing total ankle replacements. J Bone Joint Surg Br 2009;91:69-74.

15. Saltzman CL, el Khoury GY. The hindfoot alignment view. Foot Ankle Int 1995;16: 572-6.

16. Valderrabano V, Frigg A, Leumann A, et al. Total ankle arthroplasty in valgus ankle osteoarthritis. Orthopade 2011;40:971-7 [in German]. 
17. Brinker M. Review of orthopaedic trauma. Philadelphia: Saunders-Elsevier; 2001.

18. Johnson JE, Lamdan R, Granberry WF, et al. Hindfoot coronal alignment: a modified radiographic method. Foot Ankle Int 1999;20:818-25.

19. Miller M. Review of orthopaedics. Philadelphia: Saunders-Elsevier; 2004.

20. Thomas RH, Daniels TR. Ankle arthritis. J Bone Joint Surg Am 2003;85:923-36.

21. Pagenstert GI, Hintermann B, Barg A, et al. Realignment surgery as alternative treatment of varus and valgus ankle osteoarthritis. Clin Orthop Relat Res 2007; 462:156-68.

22. Takakura Y, Takaoka T, Tanaka Y, et al. Results of opening-wedge osteotomy for the treatment of a post-traumatic varus deformity of the ankle. J Bone Joint Surg Am 1998;80:213-8.

23. Stamatis ED, Cooper PS, Myerson MS. Supramalleolar osteotomy for the treatment of distal tibial angular deformities and arthritis of the ankle joint. Foot Ankle Int 2003;24:754-64.

24. Buckwalter JA, Saltzman C, Brown T. The impact of osteoarthritis: implications for research. Clin Orthop Relat Res 2004;S6-15.

25. Buckwalter JA, Brown TD. Joint injury, repair, and remodeling: roles in posttraumatic osteoarthritis. Clin Orthop Relat Res 2004;7-16.

26. Felson DT. Risk factors for osteoarthritis: understanding joint vulnerability. Clin Orthop Relat Res 2004;S16-21.

27. McKinley TO, Rudert MJ, Koos DC, et al. Pathomechanic determinants of posttraumatic arthritis. Clin Orthop Relat Res 2004;S78-88.

28. Steffensmeier SJ, Saltzman CL, Berbaum KS, et al. Effects of medial and lateral displacement calcaneal osteotomies on tibiotalar joint contact stresses. J Orthop Res 1996;14:980-5.

29. Knupp M, Stufkens SA, van Bergen CJ, et al. Effect of supramalleolar varus and valgus deformities on the tibiotalar joint: a cadaveric study. Foot Ankle Int 2011; 32:609-15.

30. Chou LB, Coughlin MT, Hansen S Jr, et al. Osteoarthritis of the ankle: the role of arthroplasty. J Am Acad Orthop Surg 2008;16:249-59.

31. Deland JT, de Asla RJ, Segal A. Reconstruction of the chronically failed deltoid ligament: a new technique. Foot Ankle Int 2004;25:795-9.

32. Valderrabano $V$, Hintermann $B$, Horisberger $M$, et al. Ligamentous posttraumatic ankle osteoarthritis. Am J Sports Med 2006;34:612-20.

33. Clarke HJ, Michelson JD, Cox QG, et al. Tibio-talar stability in bimalleolar ankle fractures: a dynamic in vitro contact area study. Foot Ankle 1991;11:222-7.

34. Harper MC. Deltoid ligament: an anatomical evaluation of function. Foot Ankle 1987;8:19-22.

35. Earll M, Wayne J, Brodrick C, et al. Contribution of the deltoid ligament to ankle joint contact characteristics: a cadaver study. Foot Ankle Int 1996;17:317-24.

36. Michelson JD, Hamel AJ, Buczek FL, et al. Kinematic behavior of the ankle following malleolar fracture repair in a high-fidelity cadaver model. J Bone Joint Surg Am 2002;84:2029-38.

37. Bluman EM, Chiodo CP. Valgus ankle deformity and arthritis. Foot Ankle Clin 2008;13:443-70, ix.

38. Bluman EM, Myerson MS. Stage IV posterior tibial tendon rupture. Foot Ankle Clin 2007;12:341-62, viii.

39. Bohay DR, Anderson JG. Stage IV posterior tibial tendon insufficiency: the tilted ankle. Foot Ankle Clin 2003;8:619-36.

40. Francisco R, Chiodo CP, Wilson MG. Management of the rigid adult acquired flatfoot deformity. Foot Ankle Clin 2007;12:317-27, vii. 
41. Giannini S, Faldini C, Acri F, et al. Surgical treatment of post-traumatic malalignment of the ankle. Injury 2010;41:1208-11.

42. Noll KH. The use of orthotic devices in adult acquired flatfoot deformity. Foot Ankle Clin 2001;6:25-36.

43. Hintermann B, Knupp M, Barg A. Osteotomies of the distal tibia and hindfoot for ankle realignment. Orthopade 2008;37:212-3 [in German].

44. Hintermann B. What the orthopaedic foot and ankle surgeon wants to know from MR imaging. Semin Musculoskelet Radiol 2005;9:260-71.

45. Knupp M, Pagenstert GI, Barg A, et al. SPECT-CT compared with conventional imaging modalities for the assessment of the varus and valgus malaligned hindfoot. J Orthop Res 2009;27:1461-6.

46. Pagenstert GI, Barg A, Leumann AG, et al. SPECT-CT imaging in degenerative joint disease of the foot and ankle. J Bone Joint Surg Br 2009;91:1191-6.

47. Outerbridge RE. The etiology of chondromalacia patellae. J Bone Joint Surg Br 1961;43:752-7.

48. Cheng YM, Huang PJ, Hong SH, et al. Low tibial osteotomy for moderate ankle arthritis. Arch Orthop Trauma Surg 2001;121:355-8.

49. Pagenstert G, Knupp M, Valderrabano V, et al. Realignment surgery for valgus ankle osteoarthritis. Oper Orthop Traumatol 2009;21:77-87.

50. Takakura Y, Tanaka Y, Kumai T, et al. Low tibial osteotomy for osteoarthritis of the ankle. Results of a new operation in 18 patients. J Bone Joint Surg Br 1995;77:50-4.

51. Stufkens SA, Knupp M, Hintermann B. Medial displacement calcaneal osteotomy. Techniques in Foot \& Ankle Surgery 2009;8:85-90.

52. Rodriguez RP. Medial displacement calcaneal tuberosity osteotomy in the treatment of posterior tibial insufficiency. Foot Ankle Clin 2001;6:545-67, viii.

53. Kelly IP, Easley ME. Treatment of stage 3 adult acquired flatfoot. Foot Ankle Clin 2001;6:153-66.

54. Kelly IP, Nunley JA. Treatment of stage 4 adult acquired flatfoot. Foot Ankle Clin 2001;6:167-78.

55. Hintermann B, Valderrabano V. Lateral column lengthening by calcaneal osteotomy. Techniques in Foot \& Ankle Surgery 2003;2:84-90.

56. Tankson CJ. The Cotton osteotomy: indications and techniques. Foot Ankle Clin 2007;12:309-15, vii.

57. Barg A, Brunner S, Zwicky L, et al. Subtalar and naviculocuneiform fusion for extended breakdown of the medial arch. Foot Ankle Clin 2011;16:69-81.

58. Cohen BE, Ogden F. Medial column procedures in the acquired flatfoot deformity. Foot Ankle Clin 2007;12:287-99, vi.

59. De Wachter J, Knupp M, Hintermann B. Double-hindfoot arthrodesis through a single medial approach. Techniques in Foot \& Ankle Surgery 2007;6:237-42.

60. Knupp M, Stufkens SA, Hintermann B. Triple arthrodesis. Foot Ankle Clin 2011; 16:61-7.

61. Coester LM, Saltzman CL, Leupold J, et al. Long-term results following ankle arthrodesis for post-traumatic arthritis. J Bone Joint Surg Am 2001;83:219-28.

62. Nihal A, Gellman RE, Embil JM, et al. Ankle arthrodesis. Foot Ankle Surg 2008; $14: 1-10$.

63. Boobbyer GN. The long-term results of ankle arthrodesis. Acta Orthop Scand 1981;52:107-10.

64. Fuchs S, Sandmann C, Skwara A, et al. Quality of life 20 years after arthrodesis of the ankle. A study of adjacent joints. J Bone Joint Surg Br 2003;85:994-8.

65. Mazur JM, Schwartz E, Simon SR. Ankle arthrodesis. Long-term follow-up with gait analysis. J Bone Joint Surg Am 1979;61:964-75. 
66. Saltzman CL, Mann RA, Ahrens JE, et al. Prospective controlled trial of STAR total ankle replacement versus ankle fusion: initial results. Foot Ankle Int 2009; 30:579-96.

67. Hintermann B, Valderrabano V, Dereymaeker G, et al. The HINTEGRA ankle: rationale and short-term results of 122 consecutive ankles. Clin Orthop Relat Res 2004;424:57-68.

68. Hintermann B, Barg A. The HINTEGRA total ankle arthroplasty. In: Wiesel SW, editor. Operative techniques in orthopaedic surgery. 1st edition. Philadelphia: Lippincott Williams \& Wilkins; 2010. p. 4022-31.

69. Hintermann B, Valderrabano V. Total ankle replacement. Foot Ankle Clin 2003;8: 375-405.

70. Hintermann B. Total ankle arthroplasty: historical overview, current concepts and future perspectives. Vienna: Springer; 2004.

71. Knupp M, Stufkens SA, Bolliger L, et al. Total ankle replacement and supramalleolar osteotomies for malaligned osteoarthritis ankle. Techniques in Foot \& Ankle Surgery 2010;9:175-81.

72. Knupp M, Stufkens SA, Bolliger L, et al. Classification and treatment of supramalleolar deformities. Foot Ankle Int 2011;32:1023-31.

73. Hintermann B, Barg A, Knupp M. Corrective supramalleolar osteotomy for malunited pronation-external rotation fractures of the ankle. J Bone Joint Surg $\mathrm{Br}$ 2011;93:1367-72.

74. Brooke BT, Harris NJ, Morgan SS. Fibula lengthening osteotomy to correct valgus mal-alignment following total ankle arthroplasty. Foot Ankle Surg 2009; 18(2):144-7.

75. Bolt PM, Coy S, Toolan BC. A comparison of lateral column lengthening and medial translational osteotomy of the calcaneus for the reconstruction of adult acquired flatfoot. Foot Ankle Int 2007;28:1115-23.

76. Hintermann B, Valderrabano V, Kundert HP. Lengthening of the lateral column and reconstruction of the medial soft tissue for treatment of acquired flatfoot deformity associated with insufficiency of the posterior tibial tendon. Foot Ankle Int 1999;20:622-9.

77. Sands AK, Tansey JP. Lateral column lengthening. Foot Ankle Clin 2007;12: 301-8, vii.

78. Hintermann B. Medial ankle instability. Foot Ankle Clin 2003;8:723-38.

79. Valderrabano V, Wiewiorski M, Frigg A, et al. Chronic ankle instability. Unfallchirurg 2007;110:691-9 [in German].

80. Lee KT, Lee YK, Young KW, et al. Perioperative complications of the MOBILITY total ankle system: comparison with the HINTEGRA total ankle system. J Orthop Sci 2010;15:317-22.

81. Myerson MS, Mroczek K. Perioperative complications of total ankle arthroplasty. Foot Ankle Int 2003;24:17-21.

82. Saltzman CL, Amendola A, Anderson R, et al. Surgeon training and complications in total ankle arthroplasty. Foot Ankle Int 2003;24:514-8.

83. Schuberth JM, Patel S, Zarutsky E. Perioperative complications of the Agility total ankle replacement in 50 initial, consecutive cases. J Foot Ankle Surg 2006;45:139-46.

84. Espinosa N, Walti M, Favre P, et al. Misalignment of total ankle components can induce high joint contact pressures. J Bone Joint Surg Am 2010;92:1179-87.

85. Fukuda T, Haddad SL, Ren Y, et al. Impact of talar component rotation on contact pressure after total ankle arthroplasty: a cadaveric study. Foot Ankle Int 2010;31:404-11. 
86. Tochigi Y, Rudert MJ, Brown TD, et al. The effect of accuracy of implantation on range of movement of the Scandinavian Total Ankle Replacement. J Bone Joint Surg $\mathrm{Br}$ 2005;87:736-40.

87. Barg A, Elsner A, Anderson AE, et al. The effect of three-component total ankle replacement misalignment on clinical outcome: pain relief and functional outcome in 317 consecutive patients. J Bone Joint Surg Am 2011;93(21): 1969-78.

88. Barg A, Suter T, Zwicky L, et al. Medial pain syndrome in patients with total ankle replacement. Orthopade 2011;40:991-9 [in German].

89. Coetzee JC. Management of varus or valgus ankle deformity with ankle replacement. Foot Ankle Clin 2008;13:509-20, x.

90. Conti SF, Wong YS. Complications of total ankle replacement. Clin Orthop Relat Res 2001;105-14.

91. Conti SF, Wong YS. Complications of total ankle replacement. Foot Ankle Clin 2002;7:791-807, vii.

92. Haskell A, Mann RA. Perioperative complication rate of total ankle replacement is reduced by surgeon experience. Foot Ankle Int 2004;25:283-9.

93. Newton SE. An artificial ankle joint. Clin Orthop Relat Res 1979;142:141-5.

94. Newton SE 3rd. An artificial ankle joint. Clin Orthop Relat Res 2004;424:3-5.

95. Newton SE 3rd. Total ankle arthroplasty. Clinical study of fifty cases. J Bone Joint Surg Am 1982;64:104-11.

96. Kirkup J. Richard Smith ankle arthroplasty. J R Soc Med 1985;78:301-4.

97. Stauffer RN, Segal NM. Total ankle arthroplasty: four years' experience. Clin Orthop Relat Res 1981;160:217-21.

98. Pyevich MT, Saltzman CL, Callaghan JJ, et al. Total ankle arthroplasty: a unique design. Two to twelve-year follow-up. J Bone Joint Surg Am 1998;80:1410-20.

99. Mclff TE, Alvine FG, Saltzman CL, et al. Intraoperative measurement of distraction for ligament tensioning in total ankle arthroplasty. Clin Orthop Relat Res 2004;111-7.

100. Vienne P, Nothdurft P. OSG-Totalendoprothese Agility: Indikationen, Operationstechnik und Ergebnisse. FussSprungg 2004;2:17-28 [in German].

101. Saltzman CL. Perspective on total ankle replacement. Foot Ankle Clin 2000;5: 761-75.

102. Greisberg J, Hansen ST Jr. Ankle replacement: management of associated deformities. Foot Ankle Clin 2002;7:721-36, vi.

103. Greisberg J, Hansen ST Jr. Total ankle arthroplasty in the advanced flatfoot. Techniques in Foot \& Ankle Surgery 2003;2:152-61.

104. Stamatis ED, Myerson MS. How to avoid specific complications of total ankle replacement. Foot Ankle Clin 2002;7:765-89.

105. Wood PL, Deakin S. Total ankle replacement. The results in 200 ankles. J Bone Joint Surg Br 2003;85:334-41.

106. Wood PL, Prem H, Sutton C. Total ankle replacement: medium-term results in 200 Scandinavian total ankle replacements. J Bone Joint Surg Br 2008;90:605-9.

107. Wood PL, Clough TM, Smith R. The present state of ankle arthroplasty. Foot Ankle Surg 2008;14:115-9.

108. Assal M, Al-Shaikh R, Reiber BH, et al. Fracture of the polyethylene component in an ankle arthroplasty: a case report. Foot Ankle Int 2003;24:901-3.

109. Takakura $Y$, Tanaka $Y$, Kumai T, et al. Ankle arthroplasty using three generations of metal and ceramic prostheses. Clin Orthop Relat Res 2004;424:130-6.

110. Tanaka Y, Takakura Y. The TNK ankle: short- and mid-term results. Orthopade 2006;35:546-51 [in German]. 
111. Greisberg J, Hansen ST, DiGiovanni C. Alignment and technique in total ankle arthroplasty. Oper Tech Orthop 2004;14:21-30.

112. Kofoed H. Scandinavian Total Ankle Replacement (STAR). Clin Orthop Relat Res 2004;424:73-9.

113. Doets HC, Brand R, Nelissen RG. Total ankle arthroplasty in inflammatory joint disease with use of two mobile-bearing designs. J Bone Joint Surg Am 2006; 88:1272-84.

114. Henricson A, Agren PH. Secondary surgery after total ankle replacement. The influence of preoperative hindfoot alignment. Foot Ankle Surg 2007;13:41-4.

115. Wood PL, Crawford LA, Suneja $R$, et al. Total ankle replacement for rheumatoid ankle arthritis. Foot Ankle Clin 2007;12:497-508.

116. Wood PL. Experience with the STAR ankle arthroplasty at Wrightington Hospital, UK. Foot Ankle Clin 2002;7:755-64.

117. Karantana A, Hobson S, Dhar S. The Scandinavian total ankle replacement: survivorship at 5 and 8 years comparable to other series. Clin Orthop Relat Res 2010;468:951-7.

118. Wood PL, Karski MT, Watmough P. Total ankle replacement: the results of 100 mobility total ankle replacements. J Bone Joint Surg Br 2010;92:958-62.

119. Ellis S, Deorio JK. The INBONE total ankle replacement. Oper Tech Orthop 2010;20:201-10.

120. Deorio JK, Easley ME. Total ankle arthroplasty. Instr Course Lect 2008;57: 383-413.

121. Skytta ET, Koivu H, Eskelinen A, et al. Total ankle replacement: a populationbased study of 515 cases from the Finnish Arthroplasty Register. Acta Orthop 2010;81:114-8.

122. Morgan SS, Brooke B, Harris NJ. Total ankle replacement by the Ankle Evolution System: medium-term outcome. J Bone Joint Surg Br 2010;92:61-5.

123. Kim BS, Knupp M, Zwicky L, et al. Total ankle replacement in association with hindfoot fusion: outcome and complications. J Bone Joint Surg Br 2010;92: 1540-7.

124. Bonasia DE, Dettoni F, Femino JE, et al. Total ankle replacement: why, when and how? lowa Orthop J 2010;30:119-30.

125. Bonnin M, Gaudot F, Laurent JR, et al. The Salto total ankle arthroplasty: survivorship and analysis of failures at 7 to 11 years. Clin Orthop Relat Res 2011;469: 225-36.

126. Bonnin M, Judet T, Colombier JA, et al. Midterm results of the Salto Total Ankle Prosthesis. Clin Orthop Relat Res 2004;424:6-18.

127. Trincat S, Kouyoumdjian P, Asencio G. Total ankle arthroplasty and coronal plane deformities. Orthop Traumatol Surg Res 2012;98:75-84. 